논문 2014-51-7-7

\title{
$\mathrm{VHF}$ 대역 통신 신호에서 $\mathrm{TDOA} / \mathrm{FDOA}$ 정보 추출을 위한 순차 추정 알고리즘
}

\section{( A Sequential Estimation Algorithm for TDOA/FDOA Extraction for VHF Communication Signals )}

\author{
김 동 규*, 김 용 희 ${ }^{* *}$, 박 진 오 $^{* *}$, 이 문 석 ${ }^{* * *}$, 박 영 미 ${ }^{* * *}$, 김 형 남** \\ ( Dong-Gyu Kim, Yong-Hee Kim, Jin-Oh Park, Moon Seok Lee, \\ Young-Mi Park, and Hyoung-Nam Kim ${ }^{\odot}$ )
}

요 약

\begin{abstract}
최근 전자전 지원 시스템 분야에서는 $\mathrm{TDOA}$ (time difference of arrival)와 $\mathrm{FDOA}$ (frequency difference of arrival) 정보를 활용한 고 정밀 위치 추정 방법에 대한 연구가 활발히 진행되고 있다. TDOA/FDOA 위치 추정 시스템은 TDOA와 FDOA 정 보를 추출하는 단계와 추출한 정보로부터 신호원의 위치를 추정하는 두 단계로 나뉘며, 정보 추출 단계에서 보편적으로 사용 하는 알고리즘으로 $\mathrm{CAF}$ (complex ambiguity function) 기반 방법이 알려져 있다. 하지만 기존의 $\mathrm{CAF}$ 기반 알고리즘은 VHF 대역의 통신 신호로부터 TDOA 및 $\mathrm{FDOA}$ 정보를 추출하는 경우, 많은 연산량으로 인해 제한된 시간에 처리하기 어려운 단점 이 있다. 따라서 본 논문에서는 통신 신호 기반 $\mathrm{TDOA} / \mathrm{FDOA}$ 정보 추출을 연산량 측면에서 효율적으로 수행하기 위해 개선 된 $\mathrm{CAF}$ 기반 순차 추정 알고리즘을 제안하고, 기존 $\mathrm{CAF}$ 기반 알고리즘과 연산량을 비교 분석한다. 또한 제안한 알고리즘의 추출 성능을 검증하기 위해 CRLB(Cramer-Lao lower bound)를 이용해 유도된 이론적 한계 성능과 비교 분석한다.
\end{abstract}

\begin{abstract}
In modern electronic warfare systems, a demand on the more accurate estimation method based on TDOA and FDOA has been increased. TDOA/FDOA localization consists of two-stage procedures; the extraction of information from signals, and the estimation of emitter location. $\mathrm{CAF}$ (complex ambiguity function) is known as a basic method in the extraction stage. However, when we extract TDOA and FDOA information from VHF(very high frequency) communication signals, conventional CAF algorithms may not work within a permitted time because of much computation. Therefore, in this paper, an improved sequential estimation algorithm based on CAF is proposed for effective calculation of extracting TDOA and FDOA estimates in terms of computational complexity. The proposed method is compared with the conventional CAF-based algorithms through simulation. In addition, we derive the optimal performance based on the CRLB(Cramer-Lao lower bound) to check the extraction performance of the proposed method.
\end{abstract}

Keywords : TDOA, FDOA, electronic warfare, CAF

\footnotetext{
* 학생회원, ** 정회원, 부산대학교 전자전기컴퓨터공학과

(Department of Electrical and Computer Engineering, Pusan National University)

*** 정회원, $\mathrm{LIG}$ 넥스원

(LIG nex1)

***** 정회원, 국방과학연구소

(Agency for Defense Development)

(c) Corresponding Author(E-mail: hnkim@pusan.ac.kr)

※ 본 논문은 2012년 국방과학연구소의 “미상신호 위치탐지 및 추적장치”에 대한 연구용역으로 지원되었음.

접수일자: 2014년04월03일, 수정일자: 2014년06월15일, 수정완료: 2014년06월30일
} 


\section{I. 서 론}

시간 지연(time delay) 및 도플러(Doppler shift) 정보 를 이용한 위치 추정에 관한 연구는 전자전 시스템, 레 이더 및 소나시스템, 위성 시스템에 이르기까지 다양한 응용 분야에 적용되는 핵심 주제이다 ${ }^{[1 \sim 3]}$. 시간 지연 및 도플러 정보를 동시에 추정하는 방법은 송신 신호와 수 신 신호 또는 두 수신 신호의 상관관계를 활용하는 $\mathrm{CAF}$ (complex ambiguity function) 기반의 다양한 알고 리즘이 제안되었다 ${ }^{[4-5]}$. 특히, 최근 전자전 지원 시스템 에서는 미상 신호원의 고정밀 위치 추정에 대한 필요성 이 증가됨에 따라 기존의 도래각 정보가 아닌 두 수신 단에서 측정된 수신 신호의 도착 시간 차이 정보인 TDOA (time difference of arrival)와 도플러 주파수 차 이인 FDOA (frequency difference of arrival)와 같은 이차(quadratic) 정보를 이용하는 방법에 관한 연구가 활발하게 진행되고 있으며, $\mathrm{TDOA}$ 와 $\mathrm{FDOA}$ 의 정보를 추출하는 방법으로 기존의 $\mathrm{CAF}$ 알고리즘을 이용하고 있다 ${ }^{[6]}$.

$\mathrm{TDOA}$ 및 $\mathrm{FDOA}$ 동시 추정을 위한 $\mathrm{CAF}$ 는 식 (1)과 같이 정의된다.

$$
A(\tau, \nu)=\int_{0}^{T} r_{1}(t) r_{2}^{*}(t+\tau) e^{-j 2 \pi \nu t}
$$

여기서 *는 복소 공액(complex conjugate)이며, 수집 시 간 $T$ 초 동안의 복소 신호(complex signal) $r_{1}(t)$ 와 $r_{2}(t)$ 를 이용하여 $\mathrm{CAF}$ 의 절대값, $|A(\tau, \nu)|$ 가 최대가 되는 시간이동 $\tau$ 와 주파수 이동 $\nu$ 로부터 $\mathrm{TDOA}$ 와 $\mathrm{FDOA}$ 값을 추출한다. 즉, 복소 신호 $r_{1}(t)$ 와 시간 이동 및 주파수 이동을 수행한 $r_{2}(t)$ 간의 상관관계가 가장 높을 때의 파라미터 값이 $\mathrm{TDOA} / \mathrm{FDOA}$ 정보의 추정치 가 된다.

$\mathrm{CAF}$ 를 기반으로 하는 알고리즘 중에서 가장 기초적 인 brute-force 알고리즘은 고려하는 모든 시간 이동 및 주파수 이동에 대하여 식 (1)의 $\mathrm{CAF}$ 연산을 수행한 뒤 전수 조사를 수행하여 최댓값을 찾는 방법이다 ${ }^{[7]}$. Brute-force 방법은 설정하는 시간 이동 및 주파수 이 동의 간격에 따라 정확도가 변하게 되므로 해상도 설정 값에 따라 성능이 좋아지는 반면에, 연산량이 늘어나게 되는 단점이 있다.

이러한 brute-force 방법의 단점을 극복하기 위하여
참고문헌 [4]에서는 decimation과 동일한 효과를 바탕 으로 주파수 해상도를 유지하여 정확도는 brute-force 와 동일하면서도 주파수축 연산량을 줄일 수 있는 방법 이 제안되었다. 이러한 방법은 식 (1)의 변형을 통해 도 출이 가능하며, 본 논문에서 제안하는 알고리즘의 기초 가 되므로 $\mathrm{II}$ 장에서 상세하게 설명한다.

상기의 방법 외에도 상관잡음을 고려한 환경에서 고 차 통계치를 이용한 방법 ${ }^{[8]}$, 광대역 신호를 고려한 방 법 $^{[9]}$ 및 다중경로채널을 고려하는 방법 ${ }^{[10]}$ 등의 현실적 환경을 적용한 알고리즘에 대한 연구도 진행되었다. 이 처럼 $\mathrm{CAF}$ 기반 알고리즘과 관련하여 연산량 감소 혹 은 정확도를 향상시키기 위한 다양한 연구가 수행되고 있다.

본 논문에서 고려하는 전자전 환경의 $\mathrm{VHF}$ 대역 통 신 신호의 경우, $\mathrm{L}$ 대역 $(1 \mathrm{GHz} \sim 2 \mathrm{GHz}), \mathrm{S}$ 대역 $(2 \mathrm{GHz}$ $4 \mathrm{GHz}$ ) 또는 그 이상의 주파수를 사용하는 레이더 신호 에 비해 도플러 주파수가 상대적으로 작은 값으로 발 생한다. 또한, 신호 스펙트럼의 대역폭이 좁은 특성을 가지므로 식 (1)에 의한 $\mathrm{CAF}$ 는 시간 축으로 넓고 주파 수 축으로 좁은 특성을 가진다. 이러한 환경에서, 수집 시간이 짧은 경우에는 주파수 축 샘플 간의 간격이 $\mathrm{FDOA}$ 값보다 커지므로 주파수 영역의 연산이 무의미 해진다. 그러므로 zero padding 과정을 통해 주파수 해 상도를 높이는 과정이 반드시 필요하게 되는데, 이로 인해 연산량이 증가하는 문제를 수반한다.

따라서 본 논문에서는 $\mathrm{VHF}$ 대역 통신 신호에서 $\mathrm{TDOA} / \mathrm{FDOA}$ 를 추출하는 환경에서 연산량을 최소화하 기 위하여 기존의 $\mathrm{CAF}$ 기반 동시 추정 알고리즘이 아 닌 $\mathrm{TDOA} / \mathrm{FDOA}$ 순차 추정 알고리즘을 제안한다. 이 때, 주파수 축 연산 시에 참고문헌 [4]에서 제안된 fine-mode 알고리즘을 도입한다. 또한, $\mathrm{CRLB}$ (Cramer-Lao lower bound) 분석을 통해 얻어진 이론적 한계 값을 알고리즘의 결과와 비교 분석한다.

본 논문의 구성은 다음과 같다. II장에서 수신 신호 및 $\mathrm{TDOA} / \mathrm{FDOA}$ 의 모델을 설명하고, $\mathrm{CRLB}$ 를 이용하 여 추출 성능의 한계를 유도한다. III장에서는 제안된 알고리즘의 기본이 되는 fine-mode 알고리즘을 소개하 고, 연산량의 비효율성을 분석하여 제시한다. IV장에서 는 본 논문에서 제안하는 $\mathrm{TDOA} / \mathrm{FDOA}$ 순차 추출 알 고리즘에 대해 자세히 설명하며, $\mathrm{V}$ 장에서 모의 실험을 통해 제안한 알고리즘과 기존 알고리즘의 연산량 비교 
및 $\mathrm{CRLB}$ 를 통한 한계 성능의 분석으로 제안한 알고리 즘의 성능을 검증한다. 마지막으로 VI장에서 본 논문의 결론을 맺는다.

\section{II. 수신 신호 모델링 및 CRLB}

본 장에서는 수신 신호 및 추정해야 할 파라미터인 $\mathrm{TDOA} / \mathrm{FDOA}$ 를 모델링하고 추출 알고리즘의 한계 성 능을 분석하기 위해 TDOA 및 $\mathrm{FDOA}$ 에 대한 $\mathrm{CRLB}$ 를 유도한다.

\section{1 수신 신호 모델링}

미상 신호원으로부터 방사되는 신호 $s(t)$ 는 공간상 으로 전파되어 두 수신단에 도달하게 된다. 이 때, 도플 러 주파수 및 시간 지연이 포함된 복소 수신신호 $r_{1}(t)$ 와 $r_{2}(t)$ 는 식 (2)와 식(3)과 같이 정의된다.

$$
\begin{aligned}
& r_{1}(t)=a_{1} s\left(t-\tau_{1}\right) e^{j 2 \pi \nu_{1}\left(t-\tau_{1}\right)}+n_{1}(t) \\
& r_{2}(t)=a_{2} s\left(t-\tau_{2}\right) e^{j 2 \pi \nu_{2}\left(t-\tau_{2}\right)}+n_{2}(t)
\end{aligned}
$$

여기서 $a_{1}$ 과 $a_{2}$ 는 전파 감쇄, $\tau_{1}$ 과 $\tau_{2}$ 는 미상 신호의 전파 시점으로부터 각 수신단에 도착한 시간, $\nu_{1}$ 과 $\nu_{2}$ 는 각 수신단에서의 도플러 주파수이며, $n_{1}(t)$ 와 $n_{2}(t)$ 는 백색 가우시안 잡음으로 가정한다. $\mathrm{TDOA} / \mathrm{FDOA}$ 를 이용한 위치 추정 시스템은 식 (2)와 식 (3)을 이용하여 식 (4)와 식(5)로 정의되는 TDOA 및 $\mathrm{FDOA}$ 정보를 추 출한다.

$$
\begin{aligned}
& \tau_{12}=\tau_{1}-\tau_{2} \\
& \nu_{12}=\nu_{1}-\nu_{2}
\end{aligned}
$$

\subsection{TDOA 및 FDOA의 $\mathrm{CRLB}$}

신호 모델에 대한 파라미터의 추출 한계 성능을 이론 적으로 분석하기 위해서는 FI (Fisher Information)의 역수로 정의되는 $\mathrm{CRLB}$ 를 이용한다. 이 때, $\mathrm{FI}$ 는 관측 모델에 포함된 추정 파라미터에 대한 정보의 총량을 의 미하며 식 (6)과 같다 ${ }^{[11]}$.

$$
\mathrm{I}(\theta)=-E\left[\frac{\partial^{2} \ln p(r ; \theta)}{\partial \theta^{2}}\right]
$$

식 (6)의 $\theta$ 는 추정해야 할 파라미터, $r$ 은 샘플링된 측 정치, $p(r ; \theta)$ 는 수신 신호의 확률 밀도 함수이다. 잡음 이 백색 가우시안인 경우의 $\theta$ 에 대한 $\mathrm{FI}$ 는 식 (7)과 같 이 유도된다 ${ }^{[11]}$.

$$
\mathrm{I}(\theta)=\frac{1}{\sigma^{2}} \sum_{n=0}^{N-1}\left(\frac{\partial r[n ; \theta]}{\partial \theta}\right)^{2}
$$

여기서 $\sigma^{2}$ 은 잡음의 분산이다. 도착 시간 차이 $\tau_{12}$ 및 도플러 주파수 차이 $\nu_{12}$ 를 추정 파라미터 $\theta$ 에 적용하 면 $\mathrm{FI}$ 의 역수인 TDOA의 CRLB $\sigma_{\tau}^{2}$ 과 FDOA의 CRLB $\sigma_{\nu}^{2}$ 이 식 (8) 및 식 (9)와 같이 유도된다 ${ }^{[4,12] .}$

$$
\sigma_{\tau}^{2}=\frac{1}{4 \pi^{2} B T \gamma \beta^{2}}, \quad \beta=\sqrt{\frac{\int_{-\infty}^{\infty} f^{2}|S(f)| d f}{\int_{-\infty}^{\infty}|S(f)| d f}}
$$

$$
\sigma_{\nu}^{2}=\frac{1}{4 \pi^{2} B T_{\gamma} T_{e}^{2}}, \quad T_{e}=\sqrt{\frac{\int_{0}^{T} t^{2}|s(t)| d t}{\int_{0}^{T}|s(t)| d t}}
$$

여기서 $B$ 는 수신기의 잡음 대역폭, $T$ 는 수집시간, $\beta$ 는 rms (root mean square) 대역폭, $T_{e}$ 는 rms 수집 시 간이며 $\gamma$ 는 effective SNR로 식 (10)과 같다 ${ }^{[4]}$.

$$
\frac{1}{\gamma}=\frac{1}{2}\left[\frac{1}{\gamma_{1}}+\frac{1}{\gamma_{2}}+\frac{1}{\gamma_{1} \gamma_{2}}\right]
$$

여기서 $\gamma_{1}$ 과 $\gamma_{2}$ 는 수신단 1 및 수신단 2에서의 $\mathrm{SNR}$ 이다.

식 (8)과 식 (9)로부터 신호 및 각 파라미터에 따른 추출 성능의 이론적 한계 값을 구할 수 있으며, 이를 바 탕으로 알고리즘 성능과 이론 값 간의 비교 분석이 가 능하다.

\section{III. 기존 $\mathrm{CAF}$ 기반 알고리즘}

본 장에서는 본 논문에서 제안하는 알고리즘의 기초 가 되는 fine-mode 알고리즘을 유도하고 주요 파라미 
터 및 설계 조건에 대해 설명한다.

샘플링 시간 $T_{s}$ 로 샘플링(sampling)된 이산 신호에 대해 식 (1)의 $\mathrm{CAF}$ 를 변경하여 적용하면 다음 식 (11) 과 같이 된다.

$$
A(m, p)=\sum_{n=0}^{N-1} r_{1}[n] r_{2}^{*}[n+m] \exp \left(-j 2 \pi \frac{n p}{Q}\right)
$$

식 (11)은 I 장에서 소개한 brute-force 알고리즘으로, $Q$ 는 추출을 수행할 때 고려하는 $p$ 의 개수이다. 이 때, $N$ 을 한 블록 당 $L$ 개의 샘플을 가지는 $K$ 개의 블록으 로 나누고 $Q$ 에 $K$ 를 대입하면 식 (12)가 유도 된다 ${ }^{[4]}$.

$$
A(m, p)=\sum_{k=0}^{K-1} \sum_{i=0}^{L-1} b_{m}[k L+i] \exp \left(-j 2 \pi \frac{k p}{K}\right)
$$

여기서 $b_{m}[k L+i]$ 는 식 (13)과 같이 정의된다.

$$
b_{m}[n]=r_{1}[n] r_{2}^{*}[n+m], \quad n=k L+i
$$

식 (12)는 그림 1 과 같이 식 (13)의 결과로 이루어진 샘 플 열을 $K$ 개의 블록으로 나누고, 각각의 블록안의 $L$ 개 의 샘플들을 더해서 출력된 $K$ 개의 샘플을 입력으로 FFT를 수행하여 구현할 수 있다 ${ }^{[7]}$. 따라서 $L$ 은 decimation factor와 유사한 효과를 내므로 식 (11)에 비해서 주파수 영역 연산을 효율적으로 수행할 수 있 다. 하지만 decimation 효과로 인해 주파수 영역의 모양
이 주파수 축의 양 방향으로 $L$ 배 만큼 넓어지게 되므 로 aliasing이 발생하지 않기 위한 제약 조건으로 샘플 링 주파수 $f_{s}$ 와 다음 관계식 (14)를 만족해야 한다.

$$
L f_{\max } \ll f_{s} / 2
$$

여기서 $f_{\max }$ 는 예상되는 최대 $\mathrm{FDOA}$ 다.

\section{TDOA/FDOA 추출을 위한 순차 추정 알고리즘}

본 장에서는 $\mathrm{VHF}$ 대역 통신 신호에 대하여 $\mathrm{TDOA} / \mathrm{FDOA}$ 를 추출할 경우, 기존 $\mathrm{CAF}$ 기반 알고리 즘이 연산량 측면에서 비효율적임을 보이고 이를 개선 하기 위한 순차 추정 알고리즘을 제안한다.

두 수신기가 그림 2와 같이 일직선상에서 동일한 방 향으로 $1 \mathrm{mach}$ 의 속도로 이동하는 전자전 환경에서 $\mathrm{VHF}$ 대역의 통신 신호를 적용하면 극단적인 경우(미 상 신호원이 그림 2 의 $(a)$ 에 위치하는 경우)에 $\mathrm{FDOA}$ 는 최대 약 $600 \mathrm{~Hz}$ 까지 발생할 수 있다. 하지만 미상 신호원이 두 수신단에서 원거리에 있는 대부분의 현실 적인 상황(미상 신호원이 그림 2 의 $(b)$ 에 위치하는 경 우)에서는 수 $\mathrm{Hz}$ 에서 수십 $\mathrm{Hz}$ 의 $\mathrm{FDOA}$ 가 발생한다. 이 때, 수집 시간은 $\mathrm{TDOA}$ 혹은 $\mathrm{FDOA}$ 정보가 시간에 따라 변하지 않는 짧은 구간이어야 한다. 이러한 조건

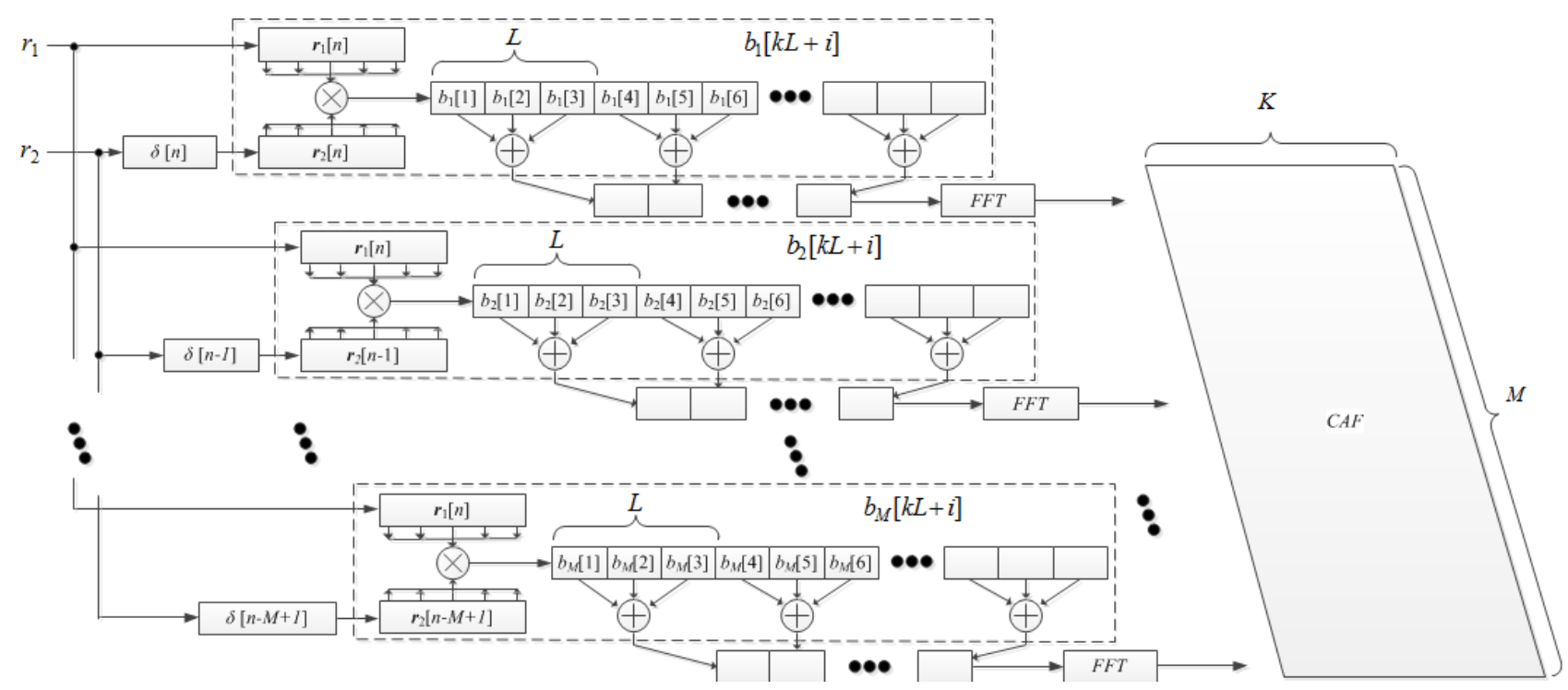

그림 1. Stein's fine-mode 알고리즘을 이용한 CAF 계산.

Fig. 1. Computation of CAF using Stein's fine-mode algorithm. 


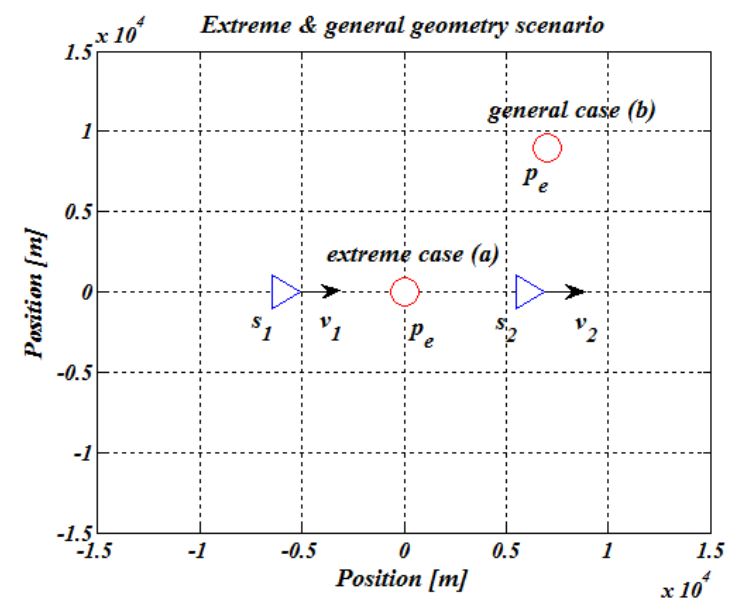

그림 2. 수신기(삼각형) 및 신호원(원)의 기하학적 배치.

Fig. 2. Deployment of sensors(triangular) \& unknown emitter(circular).

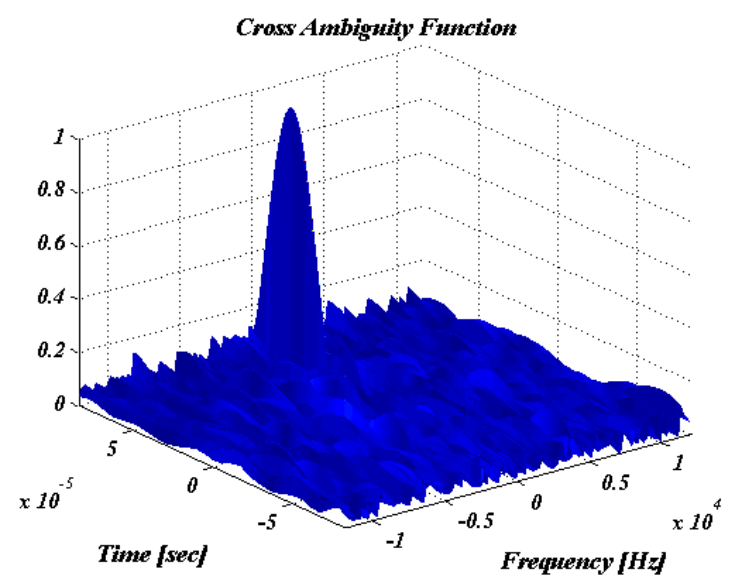

그림 3. Fine-mode 알고리즘에 의한 $\mathrm{CAF}$.

Fig. 3. CAF by fine-mode algorithm.

을 만족시키는 수집 시간 $5 \mathrm{~ms}$ 에 대하여 zero padding 과 같은 선처리가 없을 경우에 주파수 해상도는 $200 \mathrm{~Hz}$ 가 된다. 따라서 $\mathrm{FDOA}$ 가 수 수십 $\mathrm{Hz}$ 일 때, 식 (12)에 의한 $\mathrm{CAF}$ 는 그림 3 과 같고 그림 3 에 대한 주파수 축 단면인 그림 4 에서 해상도가 $200 \mathrm{~Hz}$ 인 것을 확인할 수 있다. 이 때, $\mathrm{FDOA}$ 는 주파수 해상도보다 작은 값을 가지므로 $\mathrm{CAF}$ 는 $0 \mathrm{~Hz}$ 에서 최댓값이 출력되는 것을 알 수 있고 이는 주파수 축 연산이 무의미한 것을 의미한 다. 그러므로 주파수 축 해상도를 높이기 위해서는 반 드시 zero padding이 수행 되어야 하며 그림 3에서 나 타나는 $\mathrm{CAF}$ 의 주파수 영역 전체에 대하여 zero padding을 수행할 경우, 연산량의 급격한 증가가 불가 피하다. 따라서 추정 정확도를 유지하면서 연산량을 감 소시키기 위해 $\mathrm{CAF}$ 기반 순차 추정 알고리즘을 다음

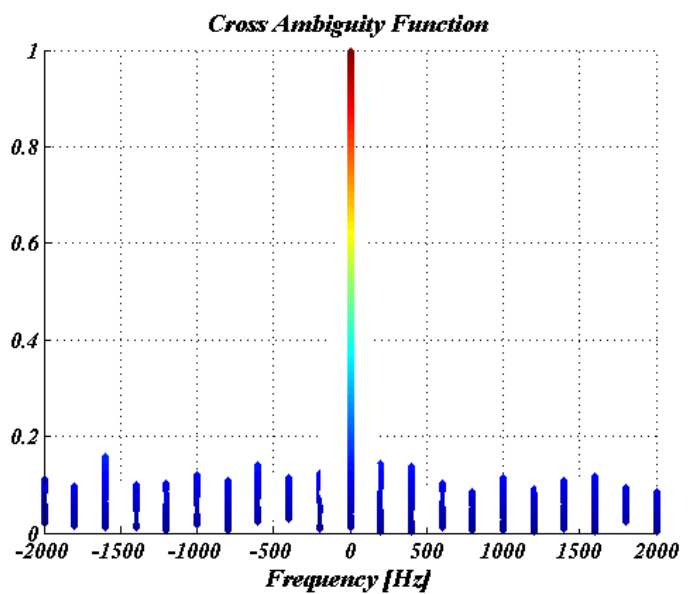

그림 4. Fine-mode 알고리즘에 의한 $\mathrm{CAF}$ 의 주파수 축. Fig. 4. Frequency axis of CAF by fine-mode algorithm.

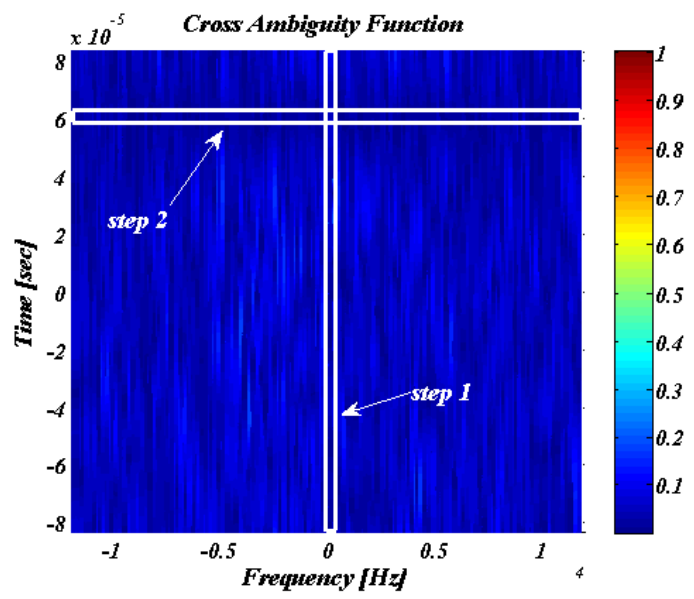

그림 5. 순차 추정 알고리즘의 단계.

Fig. 5. The step of sequential estimation algorithm.

과 같이 제안한다.

먼저, 식 (1)에 $\nu$ 를 0 으로 두고 연산을 하면 상호상 관(cross correlation)과 동일한 식이 되며 $\mathrm{CAF}$ 를 위에 서 본 단면인 그림 5 의 step 1 부분을 연산한 것과 같 다. 여기서 상호상관이 최대가 되는 시간지연 값을 찾 음으로써 $\mathrm{TDOA}$ 와 유사한 값을 추출할 수 있으며, 그 림 5의 step 2와 같이 추출한 $\mathrm{TDOA}$ 를 식 (12)에 적용 하여 zero padding을 포함한 연산을 수행하여 출력 값 이 최대가 되는 주파수 값을 $\mathrm{FDOA}$ 로 추정한다. 추정 된 $\mathrm{FDOA}$ 는 다시 식 (1)의 $\nu$ 에 적용하여 새로운 $\mathrm{TDOA}$ 값을 추출하며, $\mathrm{TDOA}$ 혹은 $\mathrm{FDOA}$ 추출값이 이전 값과 현재 값이 동일할 때까지 step 1과 step 2를 반복적으로 수행한다. 이러한 과정을 통해 추출된 $\mathrm{TDOA}$ 와 $\mathrm{FDOA}$ 는 설정한 해상도보다 높은 정확도를 

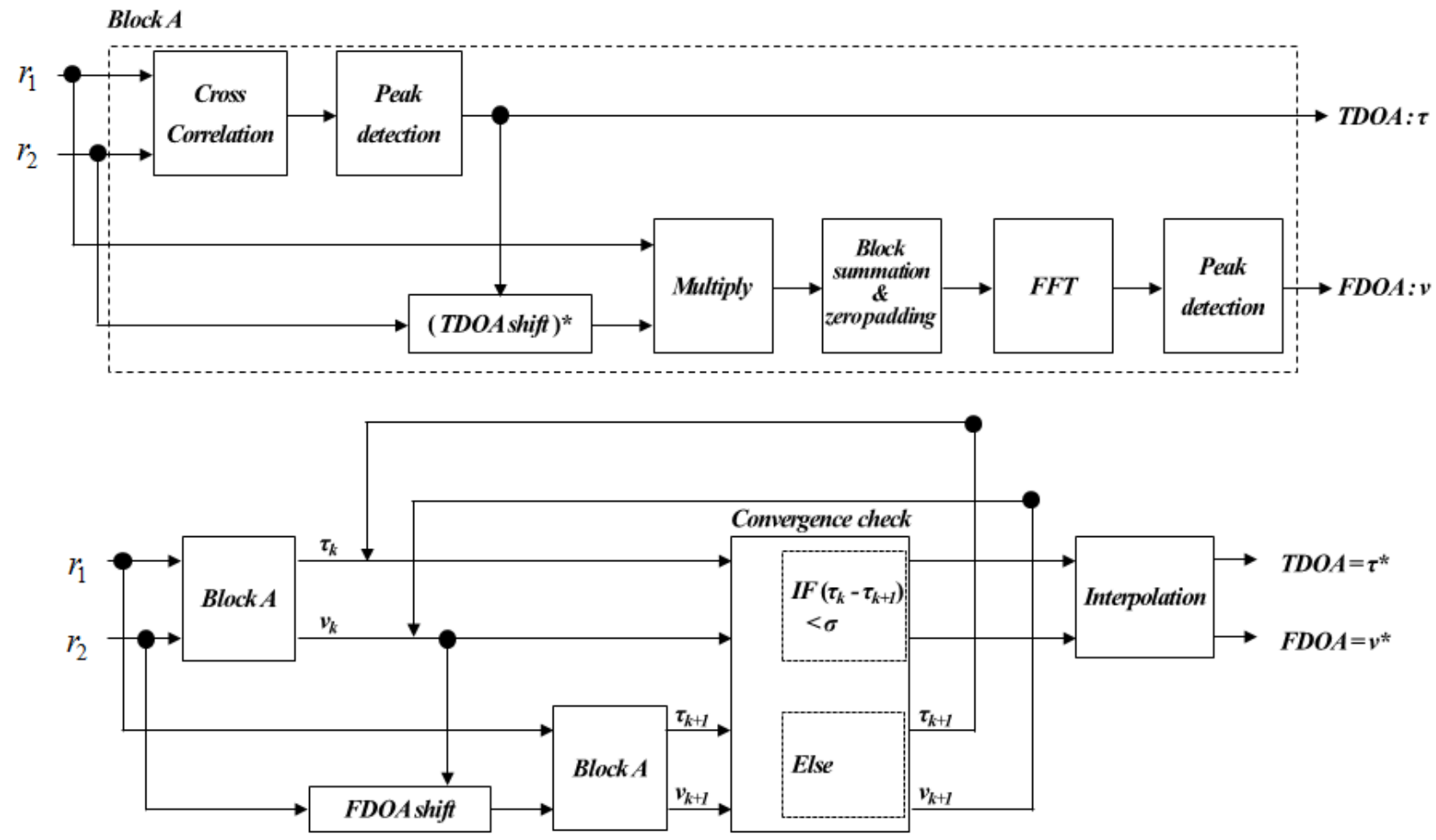

그림 6. $\mathrm{CAF}$ 기반 순차 추정 알고리즘의 블록 다이어그램.

Fig. 6. Block diagram of sequential estimation algorithm based on CAF.

위해 Jacobsen interpolation ${ }^{[13]}$ 을 수행하여 최종 TDOA $\mathrm{FDOA}$ 를 추출한다. 이러한 알고리즘의 과정을 그림 6 에 블록도로 나타내었다.

\section{V. 모의실험 결과}

본 장에서는 IV장에서 제안한 순차 추정 알고리즘의 연산량과 기존 $\mathrm{CAF}$ 기반 알고리즘의 연산량을 그래프 를 통해 비교하고 III장에서 CRLB를 이용해 유도한 $\mathrm{TDOA}$ 및 $\mathrm{FDOA}$ 추출 한계 성능을 바탕으로 알고리즘 의 추출 성능을 검증 및 분석한다.

\section{1 각 알고리즘에 대한 연산량 비교}

표 1은 brute-force, fine-mode, 그리고 제안된 알고 리즘의 연산량을 나타낸 것이다. 이 때, fine-mode와 제 안한 알고리즘에서 $(Q / L)$ 는 zero padding 후의 샘플 수와 대응되며, $k$ 는 제안된 순차 추정 알고리즘의 수렴 까지 수행되는 반복 횟수이다.

Brute-force 방법의 연산량은 정의식 (11)의 한 지점 을 연산할 때, $N$ 번의 곱셈이 필요하고 시간 축 $M$ 개와
표 1. 각 알고리즘에 대한 연산량.

Table 1. The number of operations of each algorithms.

\begin{tabular}{|c|c|}
\hline Algorithm & The number of operations \\
\hline Brute-force & $M N Q$ \\
\hline fine-mode & $M N \frac{Q}{L} \log _{2} \frac{Q}{L}$ \\
\hline proposed method & $k\left(M N+\frac{Q}{L} \log _{2} \frac{Q}{L}\right)$ \\
\hline
\end{tabular}

주파수 축 $Q$ 개의 지점 모두를 연산해야 하므로 $M N Q$ 와 같고 fine-mode는 주파수 축의 $(Q / L)$ 샘플을 $\mathrm{FFT}$ 로 수행하므로 $M N(Q / L) \log _{2}(Q / L)$ 의 연산량을 가진다. 제안하는 알고리즘은 fine-mode에서 전수 조사를 수행 하지 않고, 시간 축을 연산한 후에 주파수 축을 연산하 므로 각각을 더한 관계식으로 이루어지며, 수렴까지의 반복 횟수 $k$ 가 추가된 식으로 이루어진다.

연산량 계산을 위한 모의실험 수행 시, 샘플링 주파 수는 $160 \mathrm{MHz}$ 를 사용하였고, 수집시간을 $5 \mathrm{~ms}$ 로 설정했 으므로 총 샘플의 수 $N$ 은 800,000개가 된다. 또한, 수 신단 간 거리를 $25 \mathrm{~km}$ 로 설정하면 $M$ 은 식 (15)에 의해 


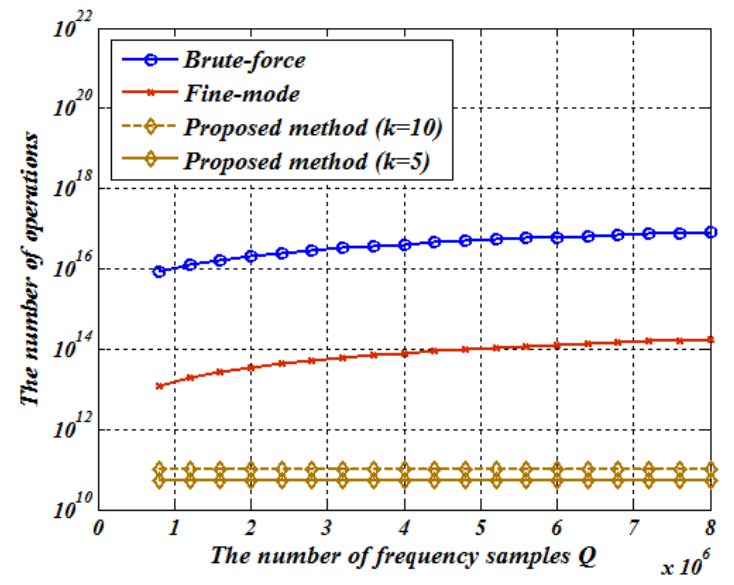

그림 7. 변수 $Q$ 에 대한 각 알고리즘 별 연산량.

Fig. 7. The number of operations of each algorithms by parameter $Q$.

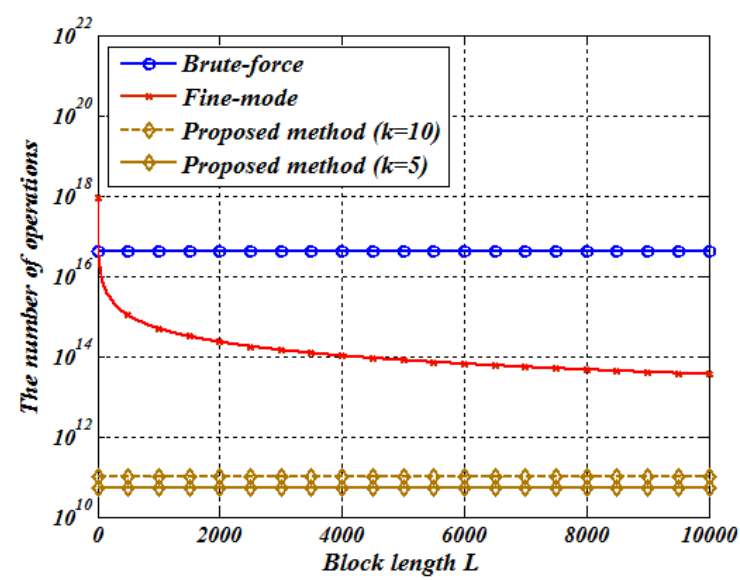

그림 8. 변수 $L$ 에 대한 각 알고리즘 별 연산량.

Fig. 8. The number of operations of each algorithm by parameter $L$.

12,800 이 된다.

$$
M=f_{s} \frac{R}{c}
$$

여기서 $R$ 은 수신단 간 거리이고, $c$ 는 전파 속도다. 이 때, 그림 7 은 $L$ 이 5,000 일 때, $Q$ 에 대한 각 알고리즘 의 연산량을 도시한 것으로 brute-force 방법과 fine-mode 방법에 비해 제안한 알고리즘의 연산량이 각각 $10^{5}$ 배, $10^{3}$ 배 이상으로 확연하게 적은 것을 확인할 수 있다. 그림 8은 $Q$ 를 샘플 수 $N$ 의 다섯 배로 설정 하고 $L$ 에 대한 연산량을 비교한 것으로 fine-mode 알 고리즘은 $L$ 이 증가함에 따라 brute-force 알고리즘에 비해 성능이 향상되는 것을 확인할 수 있으며, 제안한
알고리즘은 $L$ 에 관계없이 두 알고리즘에 비해 연산량 이 적은 것을 확인할 수 있다.

\section{2 제안한 알고리즘의 성능 및 CRLB}

본 절에서는 제안한 순차 추정 알고리즘의 $\mathrm{SNR}$ 대 비 성능을 분석하고, $\mathrm{CRLB}$ 를 이용한 추출 한계 성능을 통해 이를 검증한다.

샘플링 주파수와 수집시간은 V.1절과 동일한 $160 \mathrm{MHz}$ 및 $5 \mathrm{~ms}$ 를 이용하였으며, $4 \mathrm{PSK}, 16 \mathrm{QAM}$ 기저 대역 변조 신호를 적용하였다. 이 때, 심볼률(symbol rate)은 $40 \mathrm{kHz}$ 를 사용하였고, roll-off factor가 0인 이상 적인 shaping filter를 적용하였으며, 실제 TDOA 및 $\mathrm{FDOA}$ 는 58.8744us, $-8.0347 \mathrm{~Hz}$ 로 가정하였다. 그림 9는

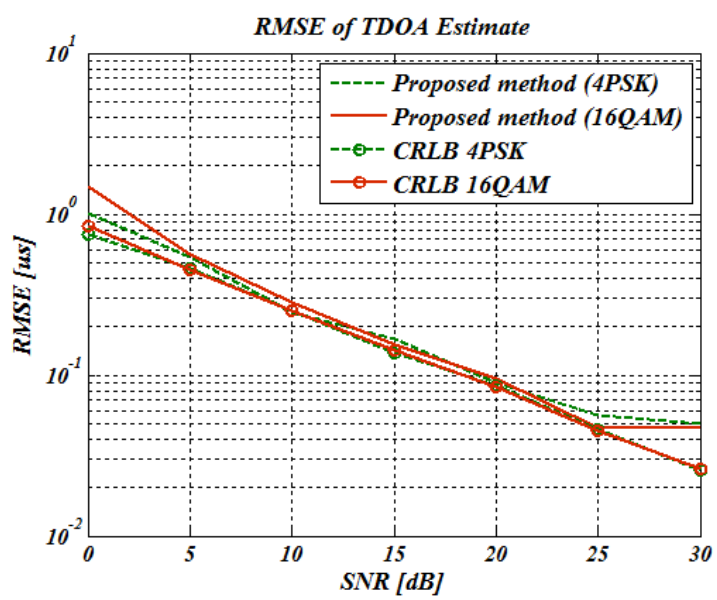

그림 9. 제안한 알고리즘의 TDOA 추정 성능 및 CRLB.

Fig. 9. Performance of TDOA estimation and CRLB for proposed method.

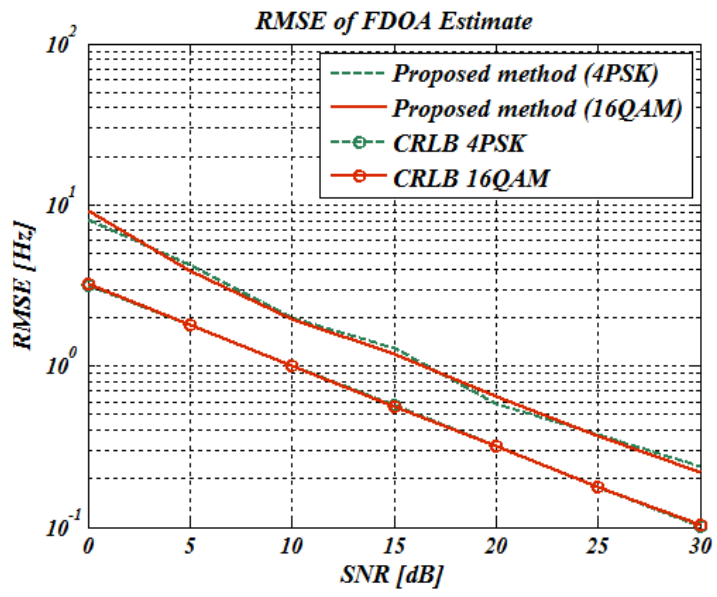

그림 10. 제안한 알고리즘의 $\mathrm{FDOA}$ 추정 성능 및 CRLB.

Fig. 10. Performance of FDOA estimation and CRLB for proposed method. 
각 $\mathrm{SNR}$ 에 대해 100회 반복 수행을 하고 $\mathrm{RMSE}$ (root mean square error)를 구하여 제안한 알고리즘의 $\mathrm{TDOA}$ 성능을 나타내었고 식 (8)에 의한 $\mathrm{TDOA}$ 의 CRLB도 함께 도시하였다. 이 때, RMSE 및 CRLB는 로그 스케일을 적용하여 선형적으로 감소하며, $25 \mathrm{~dB}$ 이 하에서 제안한 알고리즘의 성능이 한계 성능과 거의 유 사한 것을 확인할 수 있다. 그림 10은 제안한 알고리즘 의 $\mathrm{FDOA}$ 성능과 식 (9)에 의한 $\mathrm{FDOA}$ 의 $\mathrm{CRLB}$ 를 나 타낸 것이며 $\mathrm{TDOA}$ 성능과 마찬가지로 $\mathrm{SNR}$ 에 대한 $\mathrm{RMSE}$ 및 $\mathrm{CRLB}$ 는 로그스케일을 적용하면 선형적으로 감소한다. 하지만 $\mathrm{FDOA}$ 추출 성능의 경우, TDOA에 의한 오차를 수반하게 되므로 이론적 성능에 다소 미치 지 못하는 것을 확인할 수 있다.

\section{VI. 결 론}

본 논문에서는 $\mathrm{TDOA} / \mathrm{FDOA}$ 정보 추출에 이용되는 기존 $\mathrm{CAF}$ 기반 알고리즘의 연산량 측면에서의 비효율 성을 분석하고, 연산량을 효과적으로 줄일 수 있는 순 차 추정 알고리즘을 제안하였다. 또한, 제안한 알고리즘 의 성능은 모의실험 및 $\mathrm{CRLB}$ 를 이용하여 유도한 이론 적 한계 성능과의 비교 분석을 통해 검증하였다. $\mathrm{TDOA} / \mathrm{FDOA}$ 정보 추출 알고리즘의 정확도는 위치 추 정 시스템의 추정 정밀도에 영향을 미치므로, 향후 연 구에서는 제안된 알고리즘에 의해서 추출된 정보의 정 확도에 따른 위치 추정 성능과의 상관관계에 대한 분석 이 필요할 것으로 보인다.

\section{REFERENCES}

[1] M. A. Richards, Fundamentals of Radar Signal Processing, McGraw-Hill, 2005.

[2] T. Pattison and S. I. Chou, "Sensitivity analysis of dual-satellite geolocation," IEEE Trans. Aerosp. Electron. Syst., vol. 36, no. 1, pp. 56 71, Jan. 2008.

[3] Y.-H. Kim, D.-G. Kim, J.-W. Han, K.-H. Song, H.-N. Kim, "Gauss-Newton based emitter location method using successive TDOA and FDOA measurements," J. IEEK, vol. 50, no. 7, pp. 76-84, Jul. 2013.

[4] S. Stein, "Algorithm for Ambiguity Function Processing," IEEE Trans. Acoust., Speech,
Signal Process., vol. ASSP-29, no. 3, pp. 588-599, Aug. 1993.

[5] S. Stein, "Differential delay/doppler ML estimation with unknown signals," IEEE Trans. Signal Process., vol. 41, no. 8, pp. 2717-2719, Jun. 1981.

[6] G. D. Hartwell, "Improved geo-spatial resolution using a modified approach to the complex ambiguity function", Master's thesis, Naval Postgraduate School, 2005.

[7] X. Hu "Computing the Cross Ambiguity Function," Master's thesis, Dept. Electrical Engineering, Binghamton Univ., New York, 2005.

[8] D. C. Shin and C. L. Nikias, "Complex ambiguity functions using nonstationary higher order estimates," IEEE Trans. on Signal Process., vol. 43, no. 11, pp. 2649-2664, Nov. 1995.

[9] R. J. Ulman and E. Geraniotis, "Wideband TDOA/FDOA processing using summation of short-time CAF's," IEEE Trans. on Signal Process., vol. 47, no. 12, pp. 3193-3200, Dec. 1999.

[10] Y.-C. Li, D. Oh, J.-H. Kim, J.-W. Chong and J.-D. Kim, "A novel subspace-based joint TDOA and FDOA estimation using chirp signals for mobile multipath environment," International Symposium on Telecommunications (BIHTEL), Sarajevo, pp. 1-5, Oct. 2012.

[11] S. Kay, Fundamentals of Statistical Signal Processing, Volume 1, Estimation Theory, Englewood Cliffs, NJ: Prentice Hall, 1993.

[12] P. Panek, "Error analysis and bounds in time delay estimation," IEEE Trans. Signal Process., vol. 55, no. 7, pp. 3547-3549, Jul. 2007.

[13] E. Jacobsen and P. Kootsookos, "Fast, accurate frequency estimators," IEEE Trans. Signal Process., Mag., vol. 24, pp. 123-125, May. 2007. 
저 자 소 개

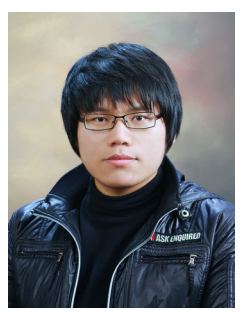

김 동 규(학생회원)

2011년 부산대학교 전자전기통신 공학부 학사 졸업.

2011년 현재 부산대학교 전자전기컴퓨터공학과 석박통합과정.

<주관심분야 : 통신 및 신호처리, 레이더 및 소나 시스템>

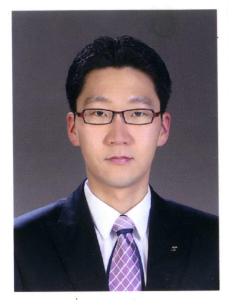

박 진 오(정회원)

2004년 명지대학교 전기정보제어 공학과 학사 졸업.

2011년 한양대학교 전자컴퓨터 통신공학과 석사 졸업.

2004년 현재 LIG넥스원 전자전 연구센터 선임 연구원

<주관심분야 : 전자전 신호처리, 방향탐지>

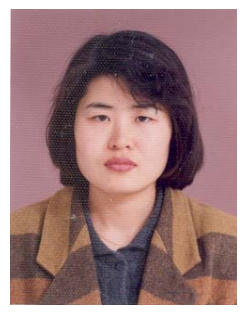

박 영 미(정회원)

1991년 충남대학교 전산과 학사 졸업.

2005년 충남대학교 컴퓨터 공학과 석사 졸업.

1991년 현재 국방과학연구소 선임연구원

<주관심분야 : 위치탐지, 신호처리>

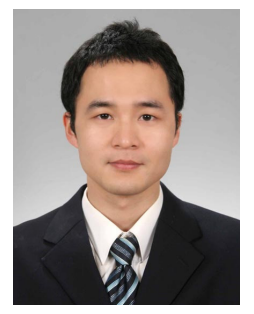

김 용 희(정회원)

2007년 부산대학교 전자전기정보 컴퓨터공학부 학사 졸업.

2009년 부산대학교 전자전기 공학과 석사 졸업.

2013년 부산대학교 전자전기 컴퓨터공학과 박사 졸업.

2014년 현재 부산대학교 전자전기컴퓨터공학과 박사 후 연구원.

<주관심분야 : 통신 및 신호처리, 레이더 및 소나 시스템, 신경디코딩>

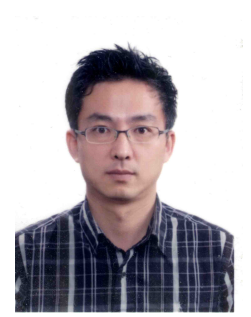

이 문 석(정회원)

1997년 조선대학교 제어계측 공학과 학사 졸업.

2010년 아주대학교 전자공학과 석사 졸업.

1997년 2000년 LG정밀 연구원
2005년 현재 LIG넥스원 전자전연구센터 수석연구원

<주관심분야 : 전자전, 임베디드 소프트웨어, 신 호처리>

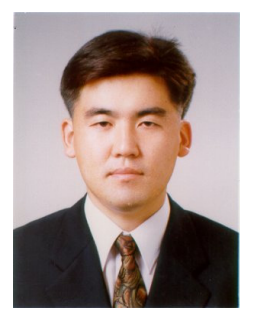

김 형 남(평생회원)-교신저자

1993년 포항공과대학교 전자전기 공학과 학사 졸업.

1995년 포항공과대학교 전자전기 공학과 석사 졸업.

2000년 포항공과대학교 전자전기 공학과 박사 졸업.

2000년 포항공과대학교 전자컴퓨터공학부 박사 후 연구원.

2000년 2003년 한국전자통신연구원

무선방송연구소 선임 연구원.

2003년 2007년 부산대학교 전자전기통신공학부 조교수.

2007년 2012년 부산대학교 전자전기공학부 부교수.

2012년 현재 부산대학교 전자공학과 교수.

<주관심분야 : 적응신호처리, 레이더 및 소나시스 템, 생체신호처리, 디지털 $\mathrm{TV}$, 디지털통신, $\mathrm{OFDM}$ 시스템> 